\title{
LANDFORM RECOGNITION IN GRANITE MOUNTAINS IN EAST ASIA (SEORAKSAN, REPUBLIC OF KOREA, AND HUANGSHAN AND SANQINGSHAN, CHINA) - A CONTRIBUTION OF GEOMORPHOLOGY TO THE UNESCO WORLD HERITAGE
}

\author{
Piotr Migońn ${ }^{1}$, Kyung-SiK WoO ${ }^{2}$, Marek KasprzaK ${ }^{1}$ \\ ${ }^{1}$ Department of Geomorphology, Institute of Geography and regional Development, University of Wrocław, \\ Poland \\ ${ }^{2}$ Department of Geology and Geophysics, Kangwon National University, Chuncheon, South Korea
}

Manuscript received: October 09, 2017

Revised version: January 31, 2018

\begin{abstract}
Migoń P., Woo K.-S., KasprzaK M, 2018. Landform recognition in granite mountains in East Asia (Seoraksan, Republic of Korea, and Huangshan and Sanqingshan, China) - a contribution of geomorphology to the UNESCO World Heritage. Quaestiones Geographicae 37(1), Bogucki Wydawnictwo Naukowe, Poznań, pp. 103-114. 7 figs.

AвSTRACT: Applied research in geomorphology includes landform analysis and evaluation from a specific perspective of scientific significance and global relevance. In this paper, landform diversity of Seoraksan, Republic of Korea, a UNESCO World Heritage candidate, is compared with geomorphic characteristics of two World Heritage properties in China, Huangshan and Sanqingshan. Seoraksan represents an almost complete mountain geomorphic system of considerable contemporary dynamics, with outstanding scenery and spectacular landforms such as domes, fins, bedrock channels, waterfalls, and inherited block fields. It is argued that Seoraksan contains outstanding scientific and aesthetic values, not present at the Chinese properties, offering scope for successful nomination.
\end{abstract}

KEY WORDS: granite geomorphology, rock control, mass movements, bedrock channels, World Heritage

Corresponding author: Piotr Migoń,piotr.migon@uwr.edu.pl

\section{Introduction}

The World Heritage Convention, adopted by UNESCO in 1972, aims at protection of the most valuable cultural and natural objects, sites and landscapes across the globe. They are inscribed on the World Heritage List in the recognition of their outstanding universal value (OUV) which needs to be demonstrated in respect to ten criteria set in the Operational Guidelines for the Implementation of the World Heritage Convention (UNESCO 2015). Four out of ten criteria refer to natural values, including two being directly relevant to geosciences. Criterion (vii) specifies that a possible World
Heritage (WH) site has to contain superlative natural phenomena or areas of exceptional natural beauty and aesthetic importance, whereas criterion (viii) indicates that potential WH sites have to be outstanding examples representing major stages of earth's history, including the record of life, significant on-going geological processes in the development of landforms, or significant geomorphic or physiographic features. It is particularly the latter which emphasizes geological and geomorphological values of an area, i.e. geoheritage. As for July 2017, 1073 World Heritage properties in total are on the WH List, located in 167 countries, including 206 natural and 35 mixed properties (WHC 2017). Among them, 90 


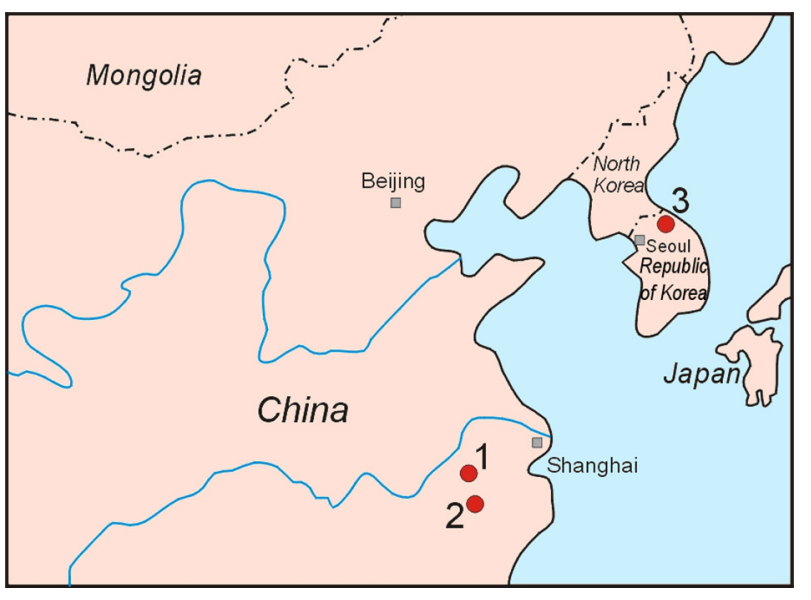

Fig. 1. Location of three granite areas mentioned in the paper in East Asia.

1 - Huangshan, 2 - Sanqingshan, 3 - Seoraksan.

properties were inscribed as having OUV residing in geoheritage values, whereas scenic beauty and superlative natural phenomena, often related to geoheritage too, are emphasized in 145 properties. In 61 of these cases, both the scientific qualities of geoheritage and the visual aspect of the landscape are given recognition and both criteria are used, including 25 cases in which only the conjunction of criteria (vii) and (viii) occurs.

The World Heritage status can only be granted to sites which represent the best possible examples of certain natural phenomena, thus the sites are widely recognized as important at the global scale, and are of interest not only to geoscientists but also to the general public. Therefore, an important part of the nomination process is comparative analysis in which characteristics and values of a property to be nominated are juxtaposed with those of existing $\mathrm{WH}$ properties, as well as other localities with similar geological and geomorphic features, to ensure that these values are indeed truly exceptional. This paper provides an example of how geomorphology can contribute to the World Heritage programme through comparative landform recognition and evaluation at three localities in East Asia, Huangshan and Sanqingshan in China and Seoraksan in the Republic of Korea (Fig. 1), which at first glance are of similar kind. All three are mountainous areas reaching similar altitude (Huangshan - 1864 m, Sanqingshan - 1817 $\mathrm{m}$, Seoraksan - $1708 \mathrm{~m}$ ), with granite as the main mountain builder and supporter of characteristic landforms. Both Chinese properties are on the WH List (Huangshan as a mixed property since 1990, with criteria (ii), (vii) and (x) used; Sanqingshan since 2007 on the basis of criterion (vii)), whereas Seoraksan is not. However, it was put on the Tentative List for the Republic of Korea as early as 1994, although the nomination criteria envisaged at that time were (vii) and (x). In order to be inscribed, its geoheritage values pertinent to criterion (viii) have to be shown not to duplicate those of the existing $\mathrm{WH}$ properties and possibly, to surpass them. For this reason, granite morphology of Seoraksan will be presented more elaborately than that of the other two mountain terrains.

\section{Framework for comparative analysis}

Although an official framework for the comparative analysis for potential World Heritage properties does not exist, the IUCN - an advisory body to the World Heritage Committee of UNESCO - recommends to use a study by Dingwall et al. (2005) as a guideline. They identified thirteen major thematic areas for geoheritage (also see Badman 2010) and the most relevant one to three localities considered here is the theme Mountain systems. It is a phrase very broad in scope and as such, may include mountain diversity in terms of geology and geological history (although this is rather covered by the Tectonic and structural features theme), physical landscape, landform inventories and ongoing processes creating and re-shaping the mountains. In fact, criterion (viii) emphasizes on-going geological processes in the development of landforms, or significant geomorphic or physiographic features, thereby defining the focus of comparative analysis within the subject matter of geomorphology.

In mountainous terrains the main geomorphic features result from an interplay of three major factors:

- Cenozoic geological history, especially the pattern and rates of uplift,

- bedrock characteristics which control rates of erosion and the shapes of medium-scale landforms, and

- climatic environment which exerts considerable control on surface processes, including those triggered by extreme weather events such as episodes of strong rainfall.

The role of climate is not limited to the contemporary conditions since mountain terrains 
have memory and many owe their principal geomorphic characteristics to Pleistocene inheritance, especially glacial.

Thus, to make comparative analysis meaningful, as a first step mountains located within one broad geographical region and representing similar geological background should be compared. This condition is satisfied by the selection of three granite mountainous terrains, although the next step for the comparative analysis should be extended to the globe. Selection of a specific rock type (i.e. granite) as a background for the analysis requires a comment. Certain rocks are known to support very distinctive landscapes (Gerrard 1988) whereas other do not leave such obvious signatures in the natural landscape. The classic examples of the former are karst-supporting limestones (e.g. Sweeting 1972, Jennings 1984, Ford and Williams 2007), sandstones (e.g. Young et al. 2009) and granites (e.g. Wilhelmy 1958, Twidale 1982, Twidale and Vidal Romaní 2005, Migoń 2006). However, while the diversity of karst is widely acknowledged and reflected in the selection of caves and karst systems as one among the thirteen Earth science themes (Badman 2010), the other lithologies do not enjoy similar recognition, even if the variety of geomorphological landscapes developed upon them is at least as impressive as on karst. For example, Migoń (2006) identified nine main types of granite morphology, although he did not attempt any in-depth analysis of mountainous terrains, labelled broadly as all-slopes landscapes (see also Twidale 1982). Thus, it is claimed that sufficient variability may be demonstrated within granite landscapes to support a World Heritage nomination.

\section{Granite morphology at Chinese World Heritage properties}

\section{Huangshan}

Huangshan (Yellow Mountains) is located in the south-eastern part of Anhui Province, along the water divide between Yangtze river in the north and Qiantang river in the south. Granites of Cretaceous age, intruded in several phases from 132 to 124 Ma ago, occupy an area of 107 $\mathrm{km}^{2}$, including the central, most elevated part of Huangshan where four peaks exceed $1800 \mathrm{~m}$ a.s.l. (Cui et al. 2009). The gross morphology of Huangshan is one of a dissected structural dome, subject to strong uplift and related erosion during the younger Cenozoic. Radial drainage is a characteristic feature of the local river network.

As a consequence of uplift pattern and progress of headward erosion, superimposed on lithological variation within the granite intrusion, a concentric arrangement of first-order landforms has developed (Cui et al. 2009). The core area is a high-altitude surface of low relief up to $200 \mathrm{~m}$, with broad troughs and several major domes at its peripheries (Fig. 2A). This conspicuous geomorphic surface is interpreted as a relict surface from pre-uplift phase of relief evolution and provisionally dated for $30 \mathrm{Ma}$ (Huang et al. 1999). It has not yet been reached by headward erosion and several major knickpoints typify the edge part. Moving beyond the edge of the central area local relief increases to hundreds of metres and isolated peaks with precipitous rock slopes dominate the morphology (Fig. 2B). Cui et al. (2009) claim that steep-sided domes gradually give way to castellated peaks and then pillars and pointed peaks, but quantitative evidence of such a transition is yet to be provided. The outer area represents ridge-and-valley topography, with altitudes up to $1300-1400 \mathrm{~m}$ and granite peaks less conspicuous. It coincides with the outcrop area of older granites, i.e. from early stages of intrusive history. At the transition to the metamorphic rock area lithologically-controlled knickpoints with waterfalls occur. In the past the presence of local glaciers in Huangshan was inferred but the purportedly glacial deposits were shown to be of mixed alluvial/colluvial origin (Helland et al. 1997).

At the local scale, granite morphology of Huangshan is clearly controlled by jointing. Joint directions vary, with NNW, NNE, NE and W-E trends being most evident (Huang et al. 2002). Joint spacing in the central part and in the inner periphery varies but is generally large. In many places one can observe continuous sub-vertical joints being tens of metres apart and horizontal joints absent. In these structural circumstances, massive domes separated by deep clefts and ravines due to preferential weathering and erosion of densely jointed zones have formed. More dense joint spacing gives rise to angular towers and pillars, but they are still quite massive. Indeed, 

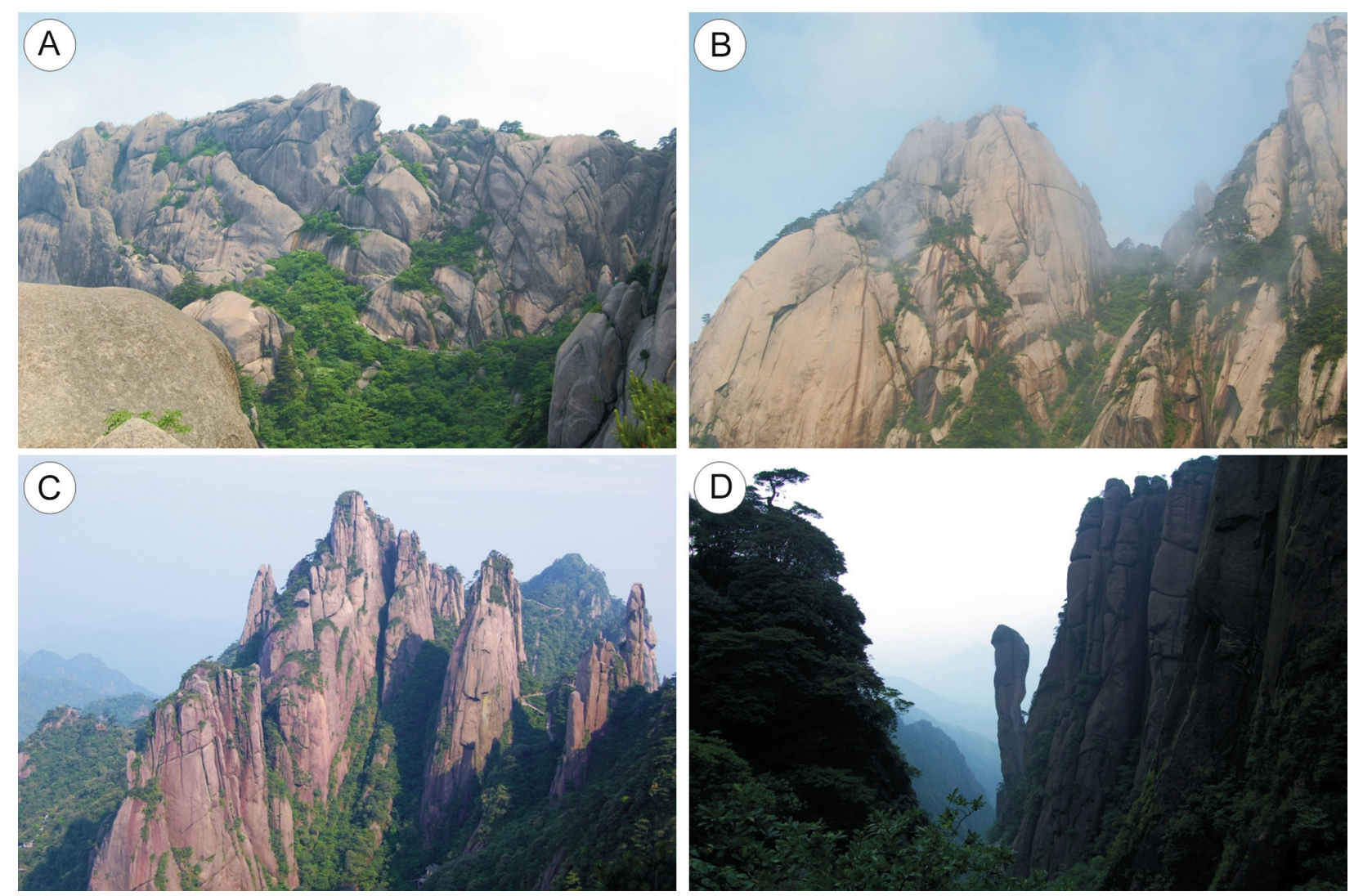

Fig. 2. Geomorphic features of Huangshan (A, B) and Sanqingshan (C, D) (Photos P. Migoń).

A - inner part of Huangshan, B - massive domes in the peripheral part of the mountain-top surface, C - rock relief dominated by vertical joints, D - deeply incised ravines, with the Giant Boa rock residual in the middle of the scene.

the bulky appearance of granite peaks has been shown as the distinctive feature of Huangshan in a review of Chinese granite landscapes (Chen et al. 2009).

\section{Sanqingshan}

Sanqingshan is a distinctive granite mountain massif located in the eastern part of Jiangxi Province that rises above the rather monotonous ridge-and-valley topography that has developed within the metamorphic rocks. Similar to Huangshan, granites of Sanqingshan are of Cretaceous age but nevertheless slightly younger. According to K-Ar dating the intrusion of the main body of granite occurred c. $115 \mathrm{Ma}$ ago, but the stock building the highest peak of the massif, Yujing (1816 $\mathrm{m}$ a.s.l.), is even younger, dated for 87-97 Ma (Yin et al. 2006). Differential crustal movements in the late Cenozoic resulted in considerable uplift, at rates apparently exceeding the mean uplift rate of the host Huaiyu Mountains, hence the Chinese geologists describe this situation as uplift-on-uplift (Yin et al. 2006). The boundaries of the elevated block are made of three fault zones, trending SSW-NNE, NW-SE, and SW-NE, respectively. Together, they enclose an area of some $30 \mathrm{~km}^{2}$, built not only of the granite of Sanqingshan, but also, in marginal parts, of Proterozoic limestone, Ordovician slate and limestone. Thus, Sanqingshan occupies much smaller area than Huangshan but with the similar range of altitudes between the valley floors and the highest peaks it appears steeper.

In contrast to Huangshan, Sanqingshan lacks an extensive planar summit surface and its most elevated part is essentially a chain of sharply pointed peaks (Migoń 2007) (Fig. 2C). The overall jointing pattern is different too. Massive compartments are very rare and there is paucity of horizontal fractures, whereas vertical jointing is ubiquitous. In consequence, the key landforms are closely spaced high conical peaks and pinnacles, tall vertical rock faces with infrequent intervening ledges and solitary columns separated by deep clefts and ravines (Fig. 2D). Among them is 
the $128 \mathrm{~m}$ high free-standing column of Giant Boa, claimed to be highest residual landform of this kind in the world. Some towers and pinnacles have acquired curious shapes due to long-term surface weathering and have been named after motives from Chinese mythology and legends.

Vertical zones of dense jointing, locally mylonitization, are weathered out to form deep and narrow clefts with no surface drainage which meet at passes separating the individual peaks. Regular valleys begin at an elevation of c. 1400 $\mathrm{m}$ a.s.l. and show V-shaped cross profiles and steep longitudinal gradients, with some residual boulders derived from rock falls and slides from the valley sides. Waterfalls occur locally at lower elevations. Chen et al. (2009) suggested that
Sanqingshan represents a more evolved topography than Huangshan, with remnants of ancient planation surface completely erased, but given the prominence of vertical jointing and the limited area it is unlikely that a broad planation surface ever existed here.

\section{Granite landforms of Seoraksan}

\section{Setting, general relief and geological background}

Seoraksan, peaking at Daecheongbong (1708 $\mathrm{m}$ a.s.1.), is located in the middle of the Korean Peninsula, in the northern part of the Republic of

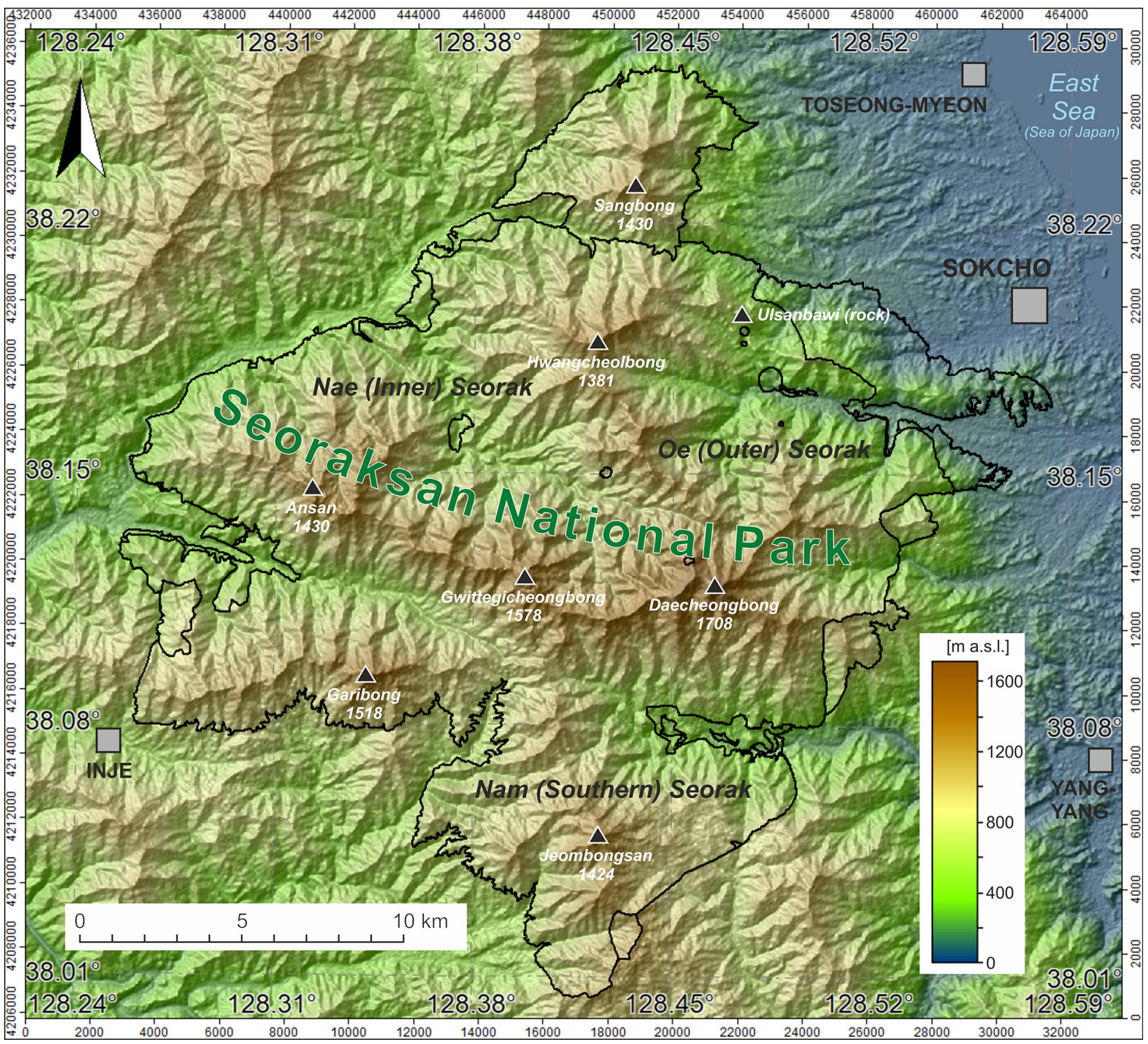

Fig. 3. General relief of Seoraksan and boundaries of the Seoraksan National Park. Source: USGS (2004), Shuttle Radar Topography Mission, 3 Arc Second scene SRTM. 
Korea, overlooking the East Sea (Sea of Japan) (Fig. 3). It forms part of the coastal mountain range of Taebaeg which runs along the eastern coast of the Korean Peninsula in NNW-SSE direction (Jo 2000). No evident topographic boundaries of Seoraksan exist on either northern or southern side. Both towards the south and the north the mountainous terrain continues, although reaching slightly lower altitudes of 1000-1500 m a.s.l. Regional tilting of the Taebaeg range to the west accounts for the topographic asymmetry of Seoraksan too. To the west the general elevation decreases gradually, while to the east it drops sharply and the narrow strip of coastal plain (2-3 km in the south; 5-10 km in the north) separates Seoraksan and the neighbouring mountains from the sea.

Seoraksan represents classic mountainous topography with narrow, often sharp-crested ridges separated by numerous deeply incised valleys as the main components (Fig. 4). In contrast to both Chinese granite mountains presented earlier, the first-order topographic feature of Seoraksan is a c. $30 \mathrm{~km}$ long ridge of west-east extension which forms the morphological axis of the mountain area and includes the highest peaks which exceed $1600 \mathrm{~m}$ a.s.l. Secondary ridges radiate towards the north whereas an east-west fault-aligned valley separates the northern and the southern part of Seoraksan, the latter being slightly lower, peaking at $1424 \mathrm{~m}$ a.s.l.

Seoraksan is built of various igneous and metamorphic rocks which considerably differ in age and testify to different stages of geotectonic evolution of the Korean Peninsula. Three main generations of rock complexes can be distinguished, of Proterozoic/early Palaeozoic, Jurassic and Cretaceous age, respectively and granites are an important component of each (Kee et al. 2010). Proterozoic rocks are represented by gneisses, locally intercalated with quartzites and amphibolites, into which several lithological variants of granites intruded. The latter have been subject to subsequent deformation and acquired certain features of metamorphic rocks such as foliation and banding. The next generation of granites is of Jurassic age, collectively known as the Daebo Granites but it consists of a few distinct lithological variants. Zircon $\mathrm{Pb}-\mathrm{U}$ ages for these granites range from 170 to $190 \mathrm{Ma}$. The youngest granites are of Cretaceous age and dated for about $88 \mathrm{Ma}$. Again, several lithological variants are present, including coarser Seoraksan granites, with porphyritic texture and locally with large, a few $\mathrm{cm}$ long potassium feldspar crystals, and finer Gwittaegicheong granites which form localized occurrences (stocks) within the more widespread Seoraksan granites.

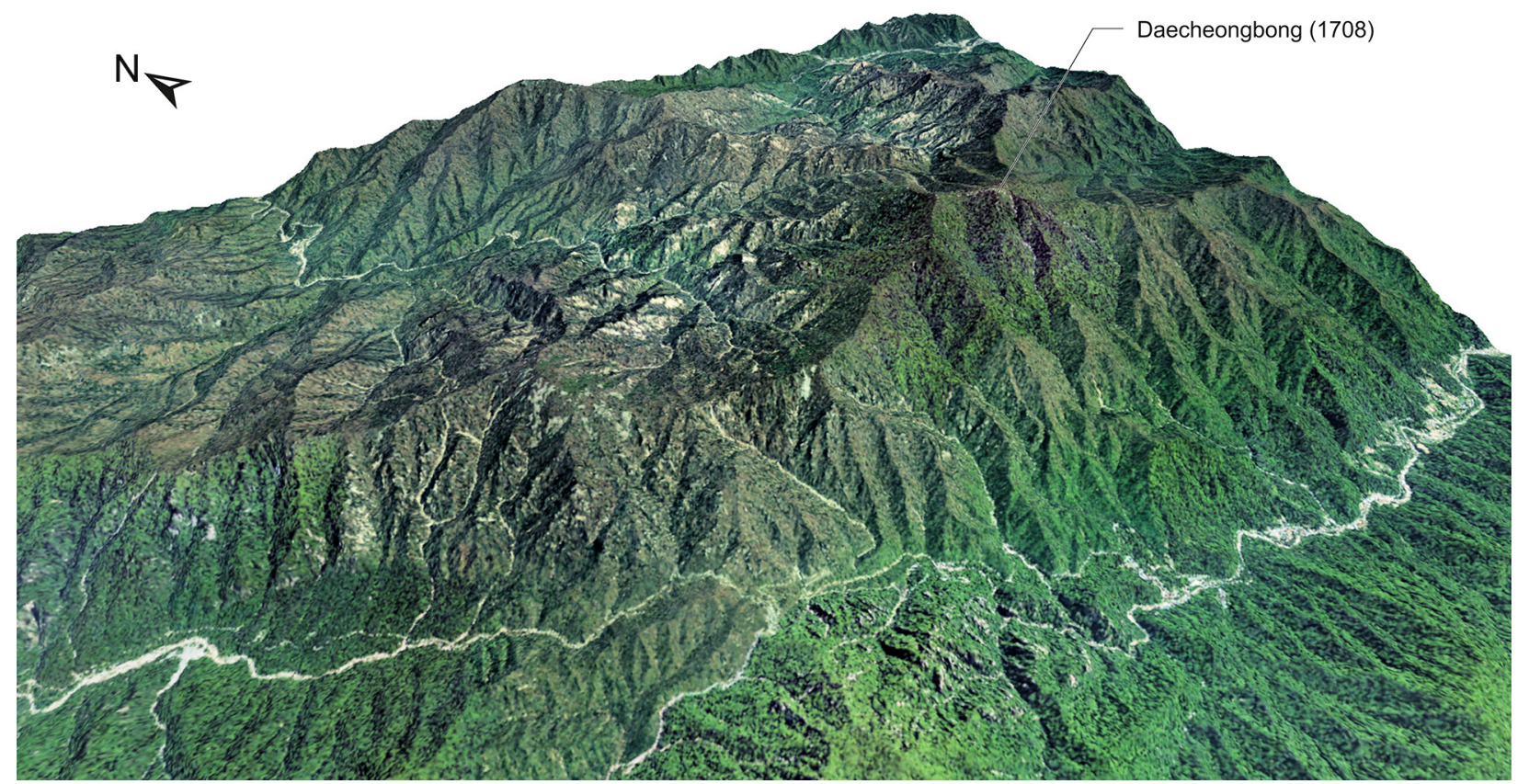

Fig. 4. Relief model of the central part of Seoraksan. Note the high degree of erosional dissection of slopes and complicated pattern of water dividing ridges.

Source: USGS (2004), Shuttle Radar Topography Mission, 3 Arc Second scene SRTM and https://www.ngii.go.kr/ kor/main/main.do?rbsIdx=1 (accessed 20 April 2017). 


\section{Rock-controlled landforms}

Lithological diversity of Seoraksan is reflected in diverse landform inventories in different bedrock types. Among them, landform assemblages in the youngest, Cretaceous granites are the most distinctive and include characteristic medium-size and minor features. The former include:

- domes and half-domes - steep-sided elevations, often with vertical slopes in lower sections and inclined surfaces in the upper sections, giving the overall convex shape. They occur in isolation or in juxtaposition. Rock slopes of domes are the highest in the area and may exceed $300 \mathrm{~m}$.

- narrow ridges (fins) - equivalents of domes developed in places where vertical joints of one predominant direction are more dense, whereas the perpendicular direction is under-represented. In such circumstances there is little scope for curved unloading joints and hence, dome morphology. Vertical walls of fins are up to $200 \mathrm{~m}$ high.

- towers - occur where vertical discontinuities have medium spacing in both principal directions, leading to the separation of the rock mass into cubic blocks. Their height is similar to ridges but ground outlines are more rectangular. Towers seem to be less common than fins and domes.

- joint-guided ravines - they are developed due to preferential weathering and erosion along zones of more dense fracturing and may account for separation of adjacent domes and fins. They lack permanent streams and channel landforms, but are used as transport routes for debris flows.

The most ubiquitous granite landforms in Seoraksan are boulders, i.e. monolithic compartments 1-10 m long, scattered on slopes and in valley floors. They have more than one origin. Some are derived from rock fall from rock slopes, while
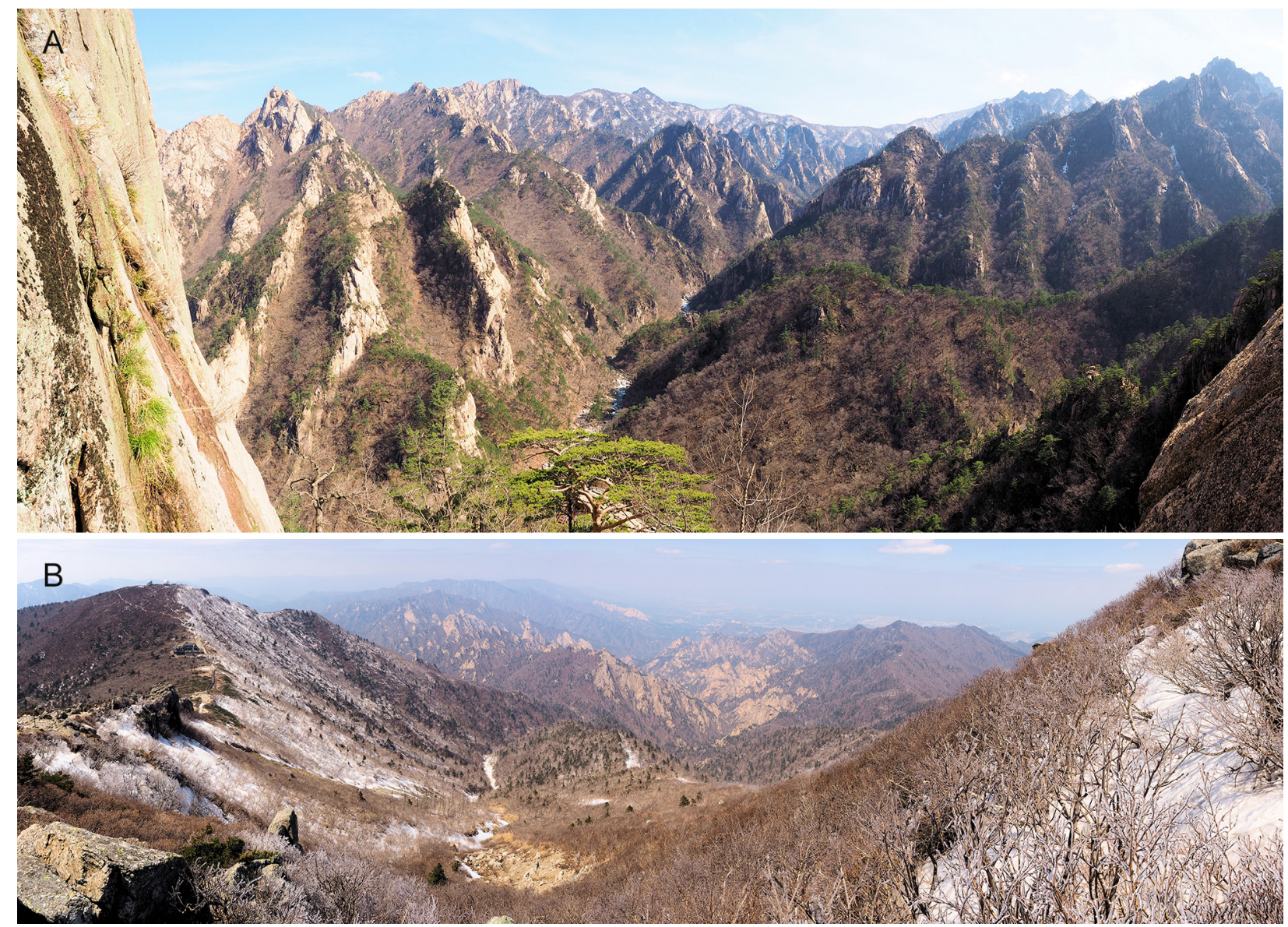

Fig. 5. Representative geomorphic landscapes on different lithologies in Seoraksan (Photos M. Kasprzak). A - abundant rock slopes, sharp-crested ridges and ravines in Cretaceous granites, B - smooth slope topography in Proterozoic granites and gneisses. 
others are excavated from deeply weathered rock mass. Minor features due to surface weathering present on outcrops of Seoraksan granites are weathering pits, runnels and flutes. However, they are neither as common nor as large as similar features of this kind present in other granite terrains (see Twidale 1982, Migoń 2006).

Morphology of terrains underlain by Proterozoic granites and gneisses stands in stark contrast to that developed upon the Creteceous granites (Fig. 5). High degree of jointing is probably responsible for the lack of impressive rock slopes, domes and fins which typify the younger granites. Slopes are more gentle, although still considerably steep $\left(30-40^{\circ}\right)$, and rock outcrops are rather few and subordinate to the general hillslope morphology (Fig. 3). In terms of shape and setting, some outcrops in water divide positions resemble classic tors known from many other granite terrains, e.g. from central and northern European countries.

Finally, landform inventories on Jurassic granites in the southern part of Seoraksan occupy an intermediate position, although morphology seems closer to that developed on Proterozoic deformed granites rather than on younger, Cretaceous granites. Dense jointing favours the development of narrow columns and slender shapes of residual rock landforms and may account for the absence of domes typical for the Cretaceous granites.

\section{Mass movements}

The evidence of mass movements is ubiquitous in Seoraksan and the resultant landforms indicate that these gravity-driven processes are often catastrophic in nature. Two most common processes are: rock falls and debris flows. Both are favoured by geological conditions and rock properties, but the actual triggers are different and the effects on geomorphology of Seoraksan are different too.

Rock falls occur on very steep rock slopes, abundant especially in the part built of the Cretaceous granites. These rocks, subject to high tensile stresses, have developed a fracture system which consists of both primary sub-vertical joints, arranged in more or less regular pattern, and secondary joints related to erosional unloading of the rock mass, i.e. sheeting joints. The latter are broadly parallel with the topographic surface and typically steeply inclined, at an angle of 40$70^{\circ}$. Along these intersecting joint planes large rock compartments are separated from the rest of the rock mass and due to combined effects of size (weight), initial position high on the slope and steepness, the movement is very fast and run-out distance is high. In this way huge granite blocks fell, rolled or slid down the slopes, eventually reaching the footslopes or the valley floors. The size of detached blocks not uncommonly reaches $10 \mathrm{~m}$ and they are essentially monolithic, with no second-order fractures. The complementary evidence are ubiquitous scars in the rock slopes above, now seen as large overhangs, alcoves, steps and wedge-shaped hollows.

Debris flows are distinctly weather-controlled phenomena, typically initiated by heavy rains, when infiltration capacity of bedrock becomes insufficient. In contrast to rock falls, they tend to occur on regolith-covered slopes. A feature favouring debris flows is the presence of steeply inclined sheeting joints at depth, beneath the regolith. Thus, the process of movement starts with slow sliding of excessively water-bearing regolith over the sheeting plane and later, after the sliding mass reaches a ravine or headwater valley, its movement becomes constrained by topography and turns into flow due to surplus water. In Seoraksan, debris flows may travel for many kilometres, completely transforming the pre-existing morphology of valley floors. Debris flow deposits are subsequently washed out, with finer material transported further away, and larger rock compartments left as residuals. The geomorphic evidence for debris flows includes scars in the upper slopes, with bedrock exposed within otherwise forested slopes, big boulders scattered in the valley floors, lateral ridges (levees) and debris fans at the junction with a main valley. The presence of all these features under variable coverage of vegetation indicates that debris flows are persistent components of the morphological system of Seoraksan.

\section{Fluvial morphology}

Seoraksan boasts a variety of fluvial landforms, many of them indicative of ongoing, fairly rapid incision into bedrock (Fig. 6). Thus, bedrock channels are abundant, especially in the headwater sections of valleys, although at many places bedrock is concealed under recent debris flow deposits. 


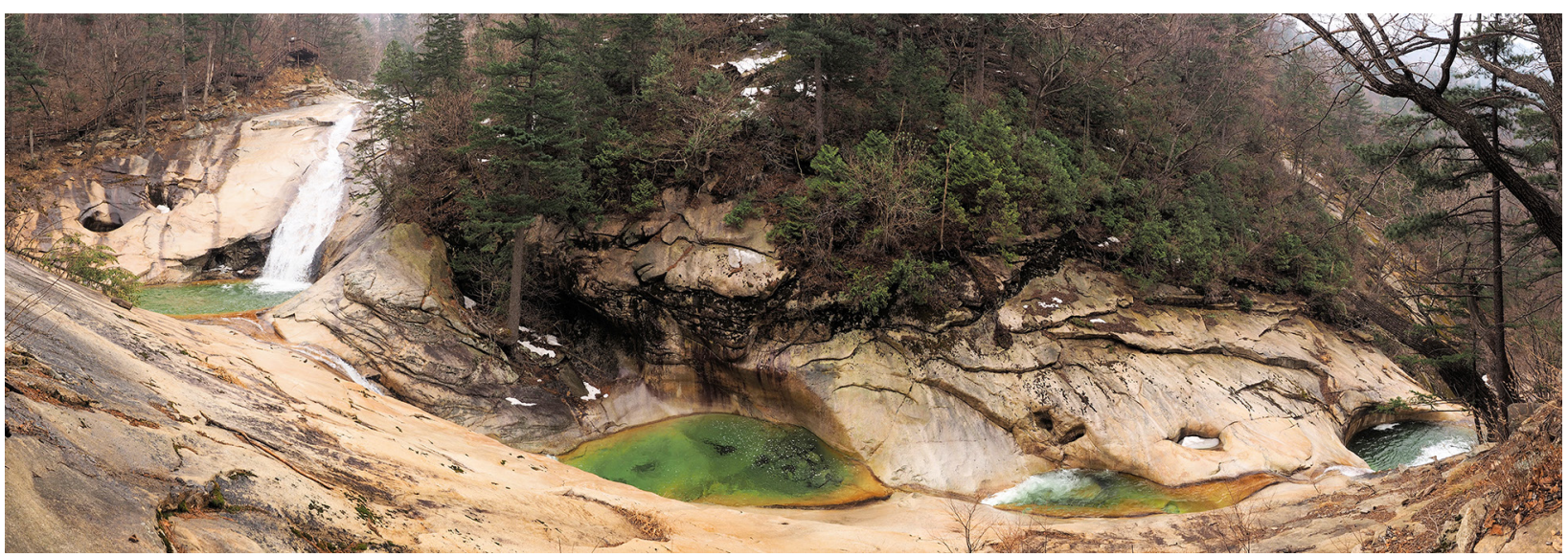

Fig. 6. Bedrock channels, waterfalls and potholes in Sibiseonnyeotang, western Seoraksan (Photo M. Kasprzak).

Longitudinal profiles of streams are highly irregular, with series of steps and more evident knickpoint zones, separating channel sections of different gradients. The most characteristic fluvial landforms testifying to ongoing incision are slot canyons and waterfalls. The former occur if bedrock discontinuities provide zones of preferential weakness and favour fluvial incision. They are tens or even hundreds of metres long, although in the latter case slot sections tend to alternate with short sections dominated by gravel deposition. Among impressive features of this kind is the slot canyon in the Cheonbuldong Valley. If such discontinuities are absent and bedrock is very massive, or the stream has low discharge and hence low erosional capacity, water flows over inclined bedrock slabs, often in staircase-like arrangement.

Waterfalls are abundant and occur in different settings. Some formed at steps across the valley floor, accounting for highly irregular stream profiles (e.g. Daeseung Fall, Seorak Fall, Biryong Falls), whereas others occur in places where a tributary stream that carries less water joins the main river with much higher discharge and is unable to keep pace with the progress of incision in the main valley. They show variable morphology too, some being simple vertical drops of water (e.g. Daeseung Fall), whereas others are more complex and consist of a series of steps and runnels oriented at different angles. The height of waterfalls varies from a mere few metres to $88 \mathrm{~m}$ at Daeseung Fall. Waterfalls and bedrock channels are typically associated with potholes. Some potholes are small-scale features c. $1 \mathrm{~m}$ across and less than $1 \mathrm{~m}$ deep, but others, especially those below large waterfalls, may have c. $10 \mathrm{~m}$ in diameter and the depth of several metres. The massiveness of granite favours the origin and enlargement of potholes.

\section{Cold-climate inheritance}

The most obvious evidence of cold-climate conditions are block fields and block slopes (Fig. 7). Depending on setting, the term block field is used for ridge-top and crest position, whereas block slope applies if the slope is steep $\left(>20^{\circ}\right)$ and some gravity-driven movement of blocks may have occurred. Block fields/slopes are generally products of in situ breakdown but some were supplied by rock fall-derived debris from steep rock walls occurring further upslope. There is correspondence between block fields/slopes occurrence and bedrock lithology. Very massive and poorly jointed Seorak granites do not readily give rise to block fields, whereas finer-grained and more jointed variants such as the Gwittaegicheongbong granite are more prone to block field formation. Around the peak of Gwittaegicheongbong the entire mountain crest is covered by blocks, which further downslope give way to block streams. Likewise, some metamorphic rocks support blocky accumulation. The size of blocks within block fields varies from less than $1 \mathrm{~m}$ to 3-4 $\mathrm{m}$ long, they are loosely packed and there may be large voids in between them. In many places block fields are unstable. It is difficult to ascertain the thickness of block fields from visual field observations only, but in numerous places it is at least 3-4 m.

Although selected block fields in Seoraksan have been studied in the past (Park 2000, 2003), many issues and problems are yet to be resolved, 


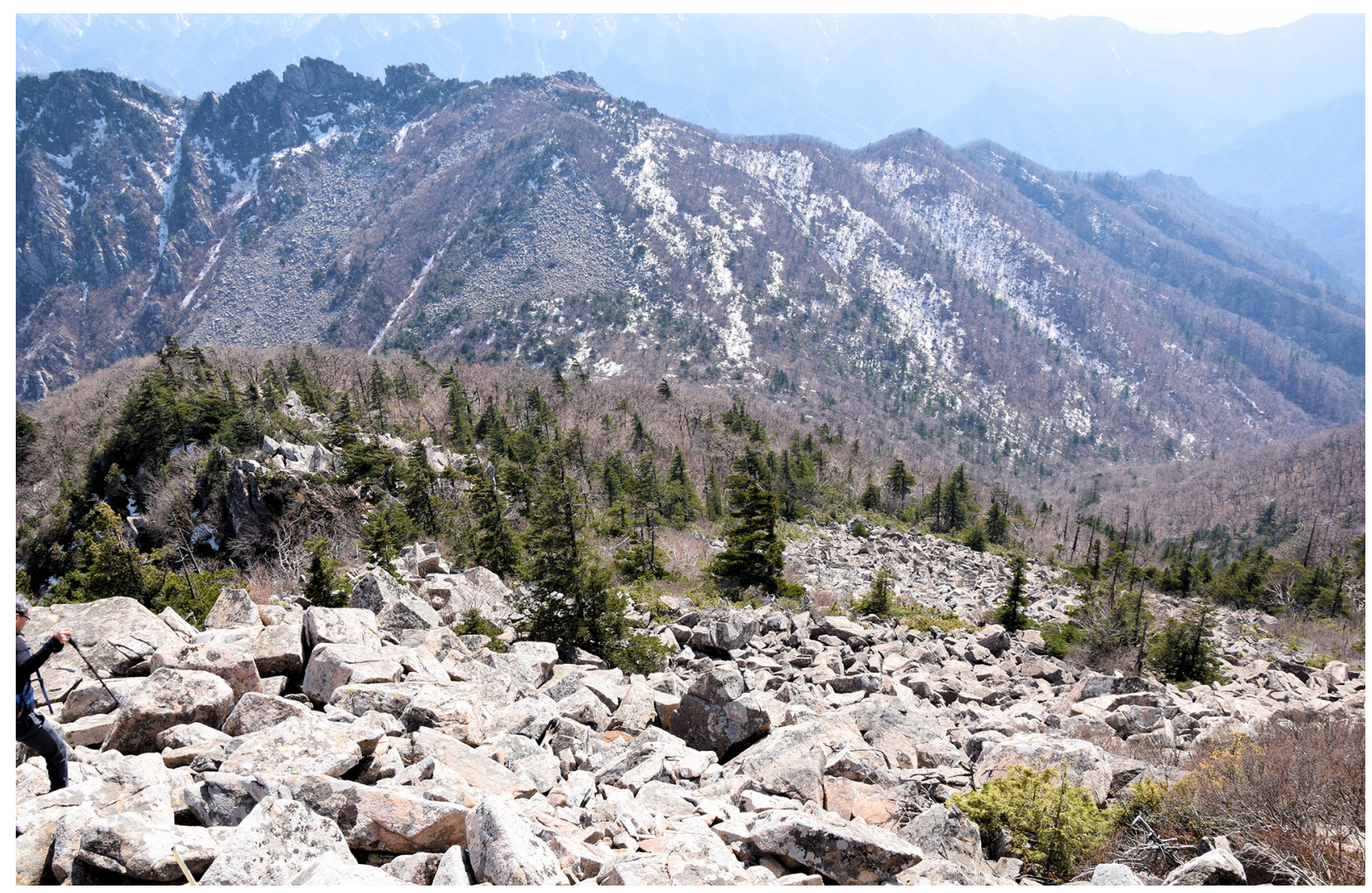

Fig. 7. Block fields on Hwangcholbong (Photo P. Migoń).

particularly regarding the complex surface morphology of the block slopes and its meaning. Field observations suggest that the relief of block fields is complex and various secondary features indicative of slow gravitational movement may be identified such as convex steps, lobes, linear furrows and closed depressions. It is possible that some extensive blocky accumulations in the upper part of Chohangnyong valley may be remnants of degraded rock glaciers but this hypothesis should be verified by further research.

\section{Comparative analysis}

Geomorphological comparative analysis serves two purposes. First, through parallel evaluation of landform diversity in different areas it leads to an informed recommendation whether nomination to be inscribed is feasible. Second, it helps to decide which nomination criteria can be used. In this context it needs to be observed that none of the Chinese properties considered here was inscribed using criterion (viii), most relevant to geoheritage.

Given bedrock similarities it is inevitable that the three areas analysed in this paper share certain common geomorphological characteristics. They abound in solid outcrops which support rock slopes a few hundred metres high, often nearly vertical, which gives dramatic appearance to the physical landscape. In each area joint control has played a major part in the evolution of landforms and a multitude of joint-guided landforms, both upstanding and concave can be identified. Frequent rock overhangs suggest that rock slope failures are an important component of contemporary geomorphic evolution, although in both Chinese massifs the respective talus deposits are not evident, possibly due to lush subtropical vegetation. Streams and rivers frequently flow over rock and scenic fluvial erosion features such as waterfalls, rock-cut troughs and potholes, are reported from each area.

Notwithstanding the above, medium-size granite landforms differ between these three areas. Huangshan is most bulky, with remnants of a planation surface in the core area encircled by clusters of massive domes and angular towers. Sanqingshan, by contrast, is essentially a group of sharply pointed peaks in its most elevated parts. Massive compartments, so characteristic for Huangshan, are very rare and there is paucity 
of horizontal fractures, whereas vertical jointing is ubiquitous. In consequence, tall vertical rock faces dominate the landscape and isolated rock columns (stone forest) occur commonly in the highest part. In Seoraksan one can find all types of granite residual landforms, including good examples of half-domes, serrated ridges and fins which are poorly represented in the Chinese properties. In addition, block fields and blocks slopes are widespread, while entirely absent in the Chinese mountains considered here. Not only are they scenic, but may be important carriers of palaeogeographical information.

However, far more important seem differences in larger scale morphology. Huangshan owes its main traits of relief to domal uplift and consequent development of radial drainage pattern, leading to dissection of its flanks. Sanqingshan too was subject to recent uplift but over a relatively small area, so that an extensive planar summit surface is absent. Seoraksan, in turn, represents more classic mountainous topography, with a hierarchical system of valleys of different order, penetrating into the core of the mountains. Remnants of ancient surfaces of low relief are not evident and alternating ridges and valleys typify regional topography. In consequence, valley morphology is as important as residual relief on divides and Seoraksan hosts superb examples of slot canyons, gorges, bedrock channels, morphologically diverse waterfalls. This contrasts with the Chinese properties where fluvial morphology is a poorly represented theme and fluvial landforms seem less scenic.

Another important feature distinguishing Seoraksan is its bedrock diversity. Various types of granite occur in Seoraksan, ranging in age from Proterozoic to Cretaceous (only Cretaceous granites are present in China), alongside various types of metamorphic and, subordinately, sedimentary and volcanic rocks. Therefore, rock landform relationships are more complex and the mountain system is more complete.

Finally, in terms of landform evolution Seoraksan appears much more dynamic than its Chinese counterparts. This is because of its location on the pathways of subtropical typhoons and the frequent occurrence of heavy rain episodes in summer. Thus, although the annual precipitation totals are similar, the pattern within the year is different. Consequently, huge debris flows and floods are frequent in Seoraksan. Regolithmantled hillslopes of Seoraksan are extensively moulded by debris slides and flows and the geomorphic legacy of these processes is evident. Thus, Seoraksan illustrates both geoheritage that goes back to the Precambrian, as well as contemporary landscape dynamics.

\section{Possible nomination criteria}

Whereas both Chinese properties were inscribed using criterion (vii) which emphasizes scenic beauty, geomorphological analysis based on landform recognition suggests that two criteria in conjunction can be potentially used in the possible nomination of Seoraksan for World Heritage.

The scope to apply criterion (viii) resides in the fact that Seoraksan arguably represents significant on-going geological processes in the development of landforms, or significant geomorphic or physiographic features. It provides an excellent example of a complex geomorphic mountain system which has many characteristics of high mountains (steepness, relative relief, proportion of rock slopes) and yet has developed in the absence of glacial processes. It demonstrates the role of granite diversity in controlling the shape of the mountains and, at the same time, highlights the role of extreme weather events in constant and significant re-making of the mountains. Debris flows are the most obvious illustrations of the power of ongoing geological processes. In-channel erosional landforms (especially waterfall chains) suggest that fluvial erosion is another significant, highly powerful process which likely proceeds in response to geologically recent uplift. The presence of several significant geomorphic features such as granite domes and fins, block fields and block slopes, slot canyons, waterfalls and rock fall deposits is the joint effect of diverse lithology, Quaternary environmental change and contemporary climatic setting. Their significance resides in abundance, size and co-existence. Together they make a highly significant mountain system, identified as one of the 13 key Earth science themes.

The undoubted scenic values of Seoraksan justify the simultaneous use of criterion (vii). Several landscape features of Seoraksan show 
exceptional natural beauty. These include the row of domes and fins forming Gongyongneungseon ridge, abundant rock slopes forming many viewing plans and diverse shapes of peaks and ridges, deep gorges with imposing rock walls towering above them (e.g. Cheonbuldong valley), series of waterfalls separated by potholes and chutes (e.g. Sibiseonnyeotang), or Buddhist monasteries inserted between granite ridges and towers (e.g. Bongjeongam).

\section{Conclusions}

The science of geomorphology can significantly assist in the implementation of the World Heritage Convention and a considerable number of WH properties were inscribed in recognition of outstanding values of their geomorphic features (Migoń 2012, 2018). The role of geomorphology is at least threefold in this context. First, comprehensive landform recognition is at the core of the scientific presentation of geoheritage values, alongside parallel presentation of geological history and rock diversity. Second, landform recognition underpins subsequent comparative analysis in which similar properties are being evaluated in terms of geoheritage values. Third, local landform inventories have to be set in the global context to make an informed statement whether a property to be nominated represents Outstanding Universal Value as understood within the World Heritage Convention. In addition, a preliminary geomorphological survey can identify knowledge gaps which have to be filled.

This paper shows how these tasks can be fulfilled, on the example of Seoraksan mountain range in the Republic of Korea which features on the national Tentative List for World Heritage. In particular, comparative analysis with similar properties within the region is highlighted. Successful nomination for World Heritage is a lengthy process in which geomorphologists have an important role to play.

\section{References}

Badman T., 2010. World Heritage and geomorphology. In: P. Migon (ed.), Geomorphological Landscapes of the World. Springer, Dordrecht - Heidelberg - London - New York: 357-368.
Cui Z., Chen Y., Yang X., 2009. Granite landform characteristics, distribution and evolution pattern in Huangshan Mt. Chinese Science Bulletin. 54(23): 4487-4499. DOI 10.1007/ s11434-009-0309-x.

Chen Y., Cui Z., Yang J., 2009. Influence of climate and tectonic movements on granite landforms in China. Journal of Geographical Sciences 19: 587-599. DOI 10.1007/s11442009-0587-x.

Dingwall P., Weighell T., Badman T., 2005. Geological World Heritage: A Global Framework. IUCN, Gland, Switzerland.

Ford D.C., Williams P.W., 2007. Karst Hydrogeology and Geomorphology. Wiley, Chichester.

Gerrard A.J., 1988. Rocks and Landforms. Unwin Hyman, London.

Helland P.E., Huang P.-H., Diffendal Jr. R.F., 1977. SEM analysis of quartz sand grain surface textures indicates alluvial/ colluvial origin of Quaternary "glacial" boulder clays at Huangshan, East-China. Quaternary Research 48: 177-186.

Huang P.-H., Diffendal R.F., Yang M.-Q., Helland P.E., 1999. Mountain Evolution and Environmental Changes of Huangshan (Yellow Mountain), China. The Journal of Chinese Geography 9(1): 25-34.

Huang P.-H., Diffendal R.F., Yang M.-Q., 2002. Structural and Geomorphological Evolution of Huangshan (Yellow Mountain), Anhui Province, China. Papers in Natural Resources 120. Online: digitalcommons.unl.edu/natrespapers/120 (accessed 17 July 2017).

Jennings J.N., 1984. Karst Geomorphology. Blackwell, Oxford.

Jo W.-R., 2000. Geology and geomorphology. In: H.-J. Kwon, W.K. Huh (eds), Korea. The Land and People. Kyohaksa, Seoul: $29-52$.

Kee W.-S., Kim H., Kim B.C., Choi S.-J., Park S.-I., Hwang S.K., 2010. Geological Report of the Seoraksan Sheet. Scale 1:50,000. Korea Institute of Geoscience and Mineral Resources.

Migoń P., 2006. Granite Landscapes of the World. Oxford University Press, Oxford.

Migoń P., 2007. Sanqinsghan - the hidden treasure of China. Geological Review (Beijing) 53(Supplement): 91-97.

Migoń P., 2012. Stories behind superlative scenery. World Heritage 63: 18-25.

Migoń P., 2018. Geoheritage and World Heritage Sites. In: Reynard E., Brilha J. (eds), Geoheritage: assessment, protection and management. Elsevier, Amsterdam: 237-249.

Park K., 2000. Morphology and genesis of block fields on the Seoraksan National Park in Kangwon Province, Korea. Journal of the Korean Geographical Society 35: 653-663.

Park K., 2003. Block fields of Seoraksan National Park: age and origin. Journal of the Korean Geographical Society 38: 922-934.

Sweeting M.M., 1972. Karst Landforms. Macmillan, London.

Twidale C.R., 1982. Granite Landforms. Elsevier, Amsterdam.

Twidale C.R., Vidal Romaní R., 2005. Landforms and Geology of Granite Terrains. Balkema, Leiden.

UNESCO, 2015. Operational Guidelines for the Implementation of the World Heritage Convention. UNESCO, Paris.

WHC [World Heritage Centre], 2017. World Heritage Convention. Online: whc.unesco.org (accessed 17 July 2017).

Wilhelmy H., 1958. Klimamorphologie der Massengesteine. Westermann, Braunschweig.

Yin G., Ma Z., Liu X., Yang Y., Yang M., Long M., 2006. Study on "Mount Sanqingshan-Type" granite geology and landscape. In: Proceedings of the First International Symposium on Geology and Geomorphology of Granite. Sanqing Mountain, China, 62-83 (English abstract).

Young R.W., Wray R.A.L., Young A.R.M., 2009. Sandstone Landforms. Cambridge University Press, Cambridge. 